\title{
1. Introduction to Creating a Healthy Organisation
}

It is widely recognised that people are the most important source of competitive advantage for organisations and there is a proven link between good people management (Beatson and Zheltoukhova, 2015), health and well-being (Health Education England, 2016), diversity (Broadbridge and Fielden, 2018), organisational support (Woolnough and Fielden, 2017) and business performance (Hunt and Fielden, 2016). According to the World Health Organisation (WHO) (Burton and WHO, 2010) the purpose of a healthy workplace means one that is supportive and accommodating of different types of workers from a diversity of backgrounds. Consequently, this book is designed to draw together the distinctive challenges in creating a healthy organisation that complies with both legal and ethical standards, and it is structured to provide the reader with a logical progression through the area. It considers the main issues and themes faced by organisations and offers new ways to approach the development of 'healthy' strategies through new understandings and practices. Recognising that healthy organisations are important to a productive workforce and economic growth, this book should be of interest to a broad international audience of organisational leaders, management academics, policy-makers, and government officials. It is specifically designed for those who wish to understand the nature of healthy organisations in both developed and developing markets. In addition, the transferability of the content of the book to all organisations should make it particularly attractive to organisations in all market sectors, especially for those in international organisations.

\section{HEALTHY ORGANISATIONS}

A healthy workplace must include health protection and health promotion, where employee health and corporate health are inextricably intertwined. It requires managers to engage in a continual improvement process to protect and promote the health, safety and well-being of all workers and the sustainability of the workplace by considering the following (Burton and WHO, 2010): 
- health and safety concerns in the physical work environment;

- health, safety and well-being concerns in the psychosocial work environment, including organisation of work and workplace culture;

- personal health resources in the workplace;

- ways of participating in the community to improve the health of workers, their families and other members of the community.

Creating a healthy workplace that does no harm to the mental or physical health, safety or well-being of workers is not just a legal but a moral imperative. Yet many organisations take advantage of workers in countries with poor or non-existent health and safety laws in order to save money in the short term, in what has been dubbed 'the race to the bottom' (Benach et al., 2007). However, many employers have recognised the moral imperative and have gone above and beyond legislated minimum standards, and are committed to their own Corporate Social Responsibility Standards (Blowfield and Murray, 2019). There are numerous case examples of enterprises that have exceeded legal requirements, to ensure that workers have not only a safe and healthy work environment, but a sustainable community as well (Burton and WHO, 2010).

\section{CHANGES IN THE WORKPLACE}

There are major changes occurring today in various aspects of work that are impacting on the experience of employees. For example, the workforce is increasing in diversity and complexity, yet barriers to recruitment, wage discrimination, job segregation, and a lack of career progression have not simply disappeared because of legislation (Broadbridge and Fielden, 2018). For example, following the tragic death of George Floyd in Minneapolis in May 2020, the Black Lives Matter (BLM) movement has re-focused our attention on the insidious impact of such racial discrimination and the stark realities of racism in our societies and in our workplaces. Research tells us that Black and minority groups are more likely to be unemployed, or in low-paid and insecure employment, compared to their White counterparts (Bhopal, 2018). Furthermore, studies have shown that Britain's Black, Asian and Minority Ethnic (BAME) workers collectively earn a staggering $£ 3.2$ billion less than their White counterparts (Henehan and Rose, 2018). Clearly, employers need to recognise the value of diversity of each individual employee if organisations are to change in terms of how people are treated, rewarded or recognised in the workplace (Tatli and Özbilgin, 2012). The nature of the workplace is also changing rapidly (and COVID-19 is likely to have a profound impact on the working world), with increased demands from globalisation of the economy and the rapid development of communication technology (Scholtz, 2020). Routine 
tasks are increasingly being performed by automation, freeing employees to take on more varied and challenging tasks. This means that employees' skills are becoming obsolete more quickly, necessitating an increasing focus on continuing training and education (Andreeva et al., 2017). Technological changes have also led to an increasing amount of poor-quality work - 'work not fit for a machine to do' - that is unsatisfying, offering low pay, low job security and unreliable hours (Scholtz, 2020). The resulting increases in workload and in job insecurity have deleterious effects on both the remaining workers and the organisation. The stress of overwork can lead to psychological problems, including depression, burnout and breakdowns, to health problems, including heart attacks and hypertension, and to organisational problems, including workplace violence or accidents (Girak, 2016; Weinberg et al., 2010). All of these problems can result in increased costs to the organisation that cancel out the short-term cost savings made by downsizing, resulting in no real improvement in long-term profitability (Andreeva et al., 2017).

\section{THE BENEFITS OF HEALTHY ORGANISATIONS}

Ensuring that employees and other stakeholders enjoy good physical and psychological well-being in the workplace should not be viewed as just a legal, regulatory burden. There are costs to organisations in terms of the loss of production through work-related illnesses, the negative impact on remaining employees (e.g. from having to take on additional work to cover for those who are off work ill), and compensation for occupational diseases (e.g. repetitive strain injury or asbestosis). In contrast, being a healthy organisation can have significant benefits, in addition to not suffering from the negative aspects of unhealthy organisations. Those benefits include:

\section{BOX 1.1 BENEFITS OF A HEALTHY ORGANISATION}

- Reduced costs.

- Reduced risks.

- Lower employee absence and turnover rates.

- Fewer accidents or near misses.

- Lessened threat of legal action.

- Improved standing among suppliers and partners.

- Better reputation for corporate responsibility among investors, customers, future employees and communities.

- Fewer days lost as employees are healthier and happier. 
- Increased productivity, because employees have greater organisational commitment, motivation and job satisfaction.

- Employees more collegiate enacting more citizenship behaviours.

- No adverse publicity.

The Taylor Review (Taylor et al., 2017, p. 6) of Modern Working Practices in the UK commissioned by HM Government, UK, states that 'while having employment is itself vital to people's health and well-being, the quality of people's work is also a major factor in helping people to stay healthy and happy, something which benefits them and serves the wider public interest'. Also, importantly, customers are becoming increasingly aware of how organisations treat their employees, their operating practices and their general attitudes towards customers, as the following case study demonstrates (Health and Safety Executive (HSE), 2018):

\section{BOX 1.2 CASE STUDY: J. SAINSBURY SUPERMARKET CHAIN}

An external health and safety audit identified a need to develop a unified approach, and also recommended more direction from the board, to develop an effective strategy impacting on employees' and customers' attitudes. The result was a radical revision of the company's approach, including: (1) the group human resources director creating a health and safety vision, supported by a plan with targets over three years, and (2) training on health and safety responsibilities being introduced for all board directors. This resulted in:

- the board providing a role model for health and safety behaviour;

- 17 per cent reduction in sickness absence;

- 28 per cent reduction in reportable incidents;

- improved morale and pride in working for the company;

- raising the profile of health and safety so it is becoming embedded in the culture of the organisation.

As a result of creating and developing a healthier working environment, Sainsbury's experienced more positive attitudes and perceptions by customers. In addition, via the internet, potential employees can gather much more information about the organisations they are looking to approach for work. There are many internet sites that list the best organisations to work for, e.g. The 
Sunday Times Best Companies to Work For list (2019), which includes lists for companies in each of the three sectors (public, private and not-for-profit). In contrast, there are also many sites that list the worst companies to work for, so if organisations want to attract the best talent they have to create a healthy place in which to work: with the internet there is nowhere to hide.

\section{DUTY OF CARE}

Employers have a duty of care towards their employees and are responsible for the creation of a healthy working environment in terms of psychological and physical health and safety (HSE, 2014). Legally, employers must abide by relevant health \& safety and employment law, for example the European Working Time Directive. This European-wide legislation arose partly from research that demonstrated that long working hours are not only a job hazard but are also a social determinant of health (Strazdins et al., 2016). The directive sets out the minimum health and safety requirements for organisations, including defining the legal parameters for minimum rest-breaks, working hours, holidays and night-time work (European Parliament and of the Council of 4, 2003). The intention of such legislation is to produce a better work-life balance and to create more efficient working practices and innovation in the workplace (Barnard et al., 2003). However, the directive has so far done little to change a long-hours culture, driven by employers' perceived needs for flexibility and workers' desire to supplement their earnings or status: employers and employees alike remain wedded to a long-hours culture (Artazcoz et al., 2016).

As well as the common law duty of care, employers also have a moral and ethical duty not to cause, or fail to prevent, physical or psychological injury, and must fulfil their responsibilities with regard to personal injury and negligence claims (Advisory, Conciliation and Arbitration Service, 2019). The legal responsibilities of employers are as follows:

\section{BOX 1.3 EMPLOYERS' LEGAL RESPONSIBILITIES}

- Assess risks to employees, customers, partners and any other people who could be affected by their activities.

- Arrange for the effective planning, organisation, control, monitoring and review of preventive and protective measures.

- Have a written health and safety policy if they employ five or more people.

- Ensure they have access to competent health and safety advice. 
- Consult employees about their risks at work and current preventive and protective measures.

The requirements facing an employer in the fulfilment of the legal aspects of a duty of care are wide-ranging and may manifest themselves in many different ways, such as:

\section{BOX 1.4 EXAMPLES OF HOW TO FULFIL DUTY OF CARE}

- Clearly define job roles and undertake risk assessments of each job.

- Ensure a safe work environment, emotionally and physically.

- Provide adequate training.

- Give constructive feedback on performance.

- Ensure that staff do not work excessive hours.

- Provide areas for rest and relaxation.

- Protect staff from bullying or harassment, either from colleagues or third parties.

- Protect staff from discrimination.

- Have policies that are accessible to all.

- Provide safe communication channels for employees to raise concerns.

- Consult employees on issues which directly concern them.

Failure to include health and safety as a key business risk in board decisions can have catastrophic results and there have been many high-profile safety cases over the years that have been rooted in failures of leadership (HSE, 2013). Failing to comply with these requirements can have serious consequences, for both organisations and individuals, with sanctions including fines, disqualification from being a future director of a company, indefinite imprisonment under the Corporate Manslaughter and Corporate Homicide Act 2007 (HSE, 2019). This does not apply just to employees but also to members of the public or anyone affected by the negligence of the organisation. An employer can be deemed to have breached their duty of care by failing to do everything that was reasonable in the circumstances to keep their employee/s safe from harm. However, employees themselves also have a responsibility for their health and well-being at work and they are entitled, by law, to refuse to undertake work that isn't safe without fear of disciplinary action. The problem with this is that, should the employee face disciplinary action for refusing to undertake a certain activity at work, the onus is on them to take their employer 
to tribunal. For the vast majority of employees this is impractical as they are often likely to be dismissed by their employer as soon as they start proceedings against their employers. This can result in workers undertaking dangerous jobs, jobs they do not have the required safety equipment for, or that they are insufficiently trained to undertake.

\section{WORLDWIDE DIFFERENCES}

Workers make up nearly half the global population and there is widespread agreement among global agencies, including the World Health Organization (WHO) and the International Labour Organization (ILO), that the health, safety and well-being of those workers is of paramount importance. The competitiveness and sustainability of organisations are dependent on the productivity of their workers, therefore it is important not only to individual workers but also to the national economy of countries and ultimately to the global economy (Burton and WHO, 2010). However, transnational organisations in developed countries frequently outsource much of their manufacturing to third world or developing countries, where prices are cheaper and attitudes towards human rights, discrimination or safety in general may be non-existent and put workers at a significantly increased risk. By utilising cheap labour in unsafe environments, organisations are able to take advantage of lax or non-existent health, safety and environmental laws or the lax enforcement of the laws (Fukuyama, 2004). It is only when something goes drastically wrong that such practices come to light for the consumer. As the legal responsibility for creating and maintaining healthy organisations is not consistent between countries, it may be assumed that the workers of transnational organisations that are based in developed countries would extend their legal, ethical and corporate governance protection to all their workers, regardless of the geographical location of their workplace. Although some transnationals (e.g., Diageo plc. and Aviva plc.) do indeed afford such protection, unfortunately not all do (e.g., GlaxoSmithKline plc. and Carnival plc.); ethics tend to be less effective motivators for organisations as they do not have monetary penalties attached (Institute of Directors, 2017).

Transnational organisations have the power and authority to bring significant political pressure to bear as they push for a substitution of institutional arrangements by forms of 'soft' regulation (Kobrin, 2009). In addition, non-Western transnational organisations are clamouring to have the same influence over the international institutional environment as those from developed countries (van Tulder, 2010). Although such developments mean that there is more potential to generate more effective governance regimes (Haas, 2004), corporate involvement in shaping governance structures is increasingly becoming detached from the democratically legitimated structure of state law (Scherer 
et al., 2013). Research on global corporate governance includes a wide array of fascinating and complex topics ranging from the structure of the board of directors to issues of transparency, responsibility and accountability (Aguilera and Crespi-Cladera, 2016). Only in the 1990s, with the advent of accounting and financial fraud by globally present firms, and concurrently, when corporate governance became consolidated as a scholarly field, did scholarship expand to incorporate cross-national comparisons within the triad (mostly US, Japan and Europe). It was not until quite recently that the study of corporate governance embraced first Asian nations (i.e., Japanese keiretsu and South Korean chaebols) and ultimately emerging markets, especially China. The more recent developments of capitalism in Asia and Latin America show that concentrated ownership structures, with relevant large shareholders as families, play a significant role. Yet global corporate governance recommendations remain at the one-rule-fits-all (Organisation for Economic Co-operation and Development (OECD), 2015), with standardised norm setting of the OECD principles that draw on the early logics of the UK Cadbury committee in 1992.

\section{STRUCTURE OF THE BOOK}

The aim of this book is to provide a contemporary review of current research and literature relating to the creation and maintenance of a healthy organisation through perception, understanding, knowledge and innovation. It presents cutting-edge research from around the globe, which addresses the key areas that organisations need to consider and the areas in which they need to challenge organisational perceptions and innovate. The book describes how to use evidence-based practice to develop, implement and evaluate change at scale and pace: these initiatives may focus on the organisation, the individual or a combination of both. However, it must always be remembered that it is an organisation's leadership that is ultimately responsible for the creation and maintenance of a healthy working environment; strong leadership is a key determinant of a healthy organisational culture (Cortina, 2008; Guediri and Griffin, 2015). The book also highlights the importance of context and process in interventions and change activities and the value of locally tailored interventions for the sustainability of practice. One of the key elements of such sustainability is the shared understanding of relevant policies, procedures and practices and the importance placed upon them by the organisation, especially in the face of competing demands (Zohar, 2010). The authors look at the creation of a healthy organisation from a psychological perspective, providing theoretical background and debates exploring the unique challenges of developing a healthy organisation, and the organisational and individual benefits that it is possible to achieve using the approaches considered. The book highlights examples of best practice wherever possible, and demonstrates 
the advantages of creating and developing a healthy organisation. The book is split into two main parts: the first part focuses on the creation of healthy organisations, whereas Part II considers how organisations can approach the development of systems to meet the challenges of change successfully and to build capacity to prepare them for the future.

Part I looks at crucial considerations in relation to health and well-being at work and considers how organisations create healthy working environments for their employees, focusing on the promotion of emotional well-being and its relationships to employee engagement, motivation and job satisfaction. It then moves on to explore diversity, as healthy organisations value all employees and provide environments which enable all employees to flourish. The book then explores the issue of Psychological Contract and its impact on health and well-being, and provides a framework for guiding organisations in the development of a psychological contract that meets the expectations of employees in the workplace. The second half of Part I explores two of the most significant issues faced by organisations in creating a healthy working environment: bullying and sexual harassment. These chapters provide information about the current thinking in these concepts, exploring the major challenges in managing these areas in practice and providing useful approaches to enable organisations to achieve greater success in addressing those challenges.

Part II provides a range of practical hands-on approaches to supporting employees through change and building these skills, techniques and knowledge in order to face new challenges more effectively. The first two chapters focus on employee development and support through coaching and mentoring in order to deal more effectively with change whilst maintaining positive relationships with the organisation. This is followed by a chapter focusing on evaluation methods to enable organisations to research and monitor their progress in developing and maintaining a healthy workforce. The issue facing all organisations is that change is a constant (and often unexpected, as in the case of COVID-19) and healthy environments have to be proactively maintained if they are to remain healthy. Each chapter provides recommendations for good practice. The final chapter looks at future trends that organisations need to consider to continue to support the health and well-being of employees in an ever-changing world. This will be more important than ever given the emerging destruction and destabilisation of certain global markets due to the impact of COVID-19 and the inevitable effect that experiences of COVID-19 will have on employees' physical health and mental well-being. At the time of writing, the extent of this is as yet unknown. The book is not structured around any specific legislation, although it does consider the implications of such legislation where appropriate. It also does not cover the physical aspects of the workplace and the dangers that can be found within them, because these unsafe environments and the risks involved in them tend to be better under- 
stood by organisations because they are less open to interpretation, whereas person-centred 'health' tends to be more ambiguous. Much of the literature also tends to be very sector centric, with those where life is most at risk (e.g., hospitals, construction, oil and gas) receiving the most attention. As a result, we have not included safety culture or climate (for a comprehensive look at safety culture see Antonsen, 2017). An organisation's safety culture is considered to provide grounds for proactive safety management by yielding 'predictive measures', for example workforce attitudes towards safety practices (i.e. propensity to take risk) were predicted by perceptions of management concern (Yule et al., 2007). The advantage of this is that such predictive measures may reduce the need to wait for the system to fail in order to identify weaknesses and to take remedial actions (Flin, 2007). Of course it does all depend on the ability to reliably assess and monitor the relevant factors that cause accidents and the willingness of those working in the organisation to change in order to reduce risk. The final chapter also considers areas where there is minimal literature, generally because it is a new research topic, such as ethics of care, environment and space, as well as psychological safety. At the time of finalising the book, the world was struck down with COVID-19 and its dreadful consequences for individuals, businesses, the financial markets and global economies. The ongoing changes for organisations that have resulted from COVID-19, some positive and some negative, are discussed more fully in the final chapter. COVID-19 is a unique (hopefully) experience that has already so radically changed working practices due to 'lock down' that the positive and negative lessons learnt from that change should not be lost.

\section{REFERENCES}

Advisory, Conciliation and Arbitration Service (2019), 'Defining an Employer's Duty of Care', accessed April 2020 at: http://www.acas.org.uk/index.aspx?articleid=3751.

Aguilera, R.V. and Crespi-Cladera, R. (2016), 'Global corporate governance: On the relevance of firms' ownership structure', Journal of World Business, 51(1), 50-57.

Andreeva, E., Brenner, M.H., Theorell, T. and Goldberg, M. (2017), 'Risk of psychological ill health and methods of organisational downsizing: A cross-sectional survey in four European countries', BMC Public Health, 17(1), 758-90.

Antonsen, S. (2017), Safety Culture: Theory, Method and Improvement, London: CRC Press.

Artazcoz, L., Cortès, I., Benavides, F.G., Escribà-Agüir, V., Bartoll, X., Vargas, H. and Borrell, C. (2016), 'Long working hours and health in Europe: Gender and welfare state differences in a context of economic crisis', Health \& Place, 40, 161-8.

Barnard, C., Deakin, S. and Hobbs, R. (2003), 'Opting out of the 48-hour week: Employer necessity or individual choice? An empirical study of the operation of Article 18 (1)(b) of the Working Time Directive in the UK', Industrial Law Journal, 32(4), 223-52.

Beatson, M. and Zheltoukhova, K. (2015), Productivity: Getting the Best out of People, Chartered Institute of Personnel Development, Policy Report, London: CIPD. 
Benach, J., Muntaner, C. and Chairs, S.V. (2007), 'Employment conditions and health inequalities', Employment Conditions Knowledge Network, Final Report to WHO Commission on Social Determinants of Health, accessed December 2018 at: http:// www.who.int/social determinants/themes/employmentconditions/en/.

Bhopal, K. (2018), White Privilege: The Myth of a Post-Racial Society, Bristol: Policy Press.

Blowfield, M. and Murray, A. (2019), Corporate Social Responsibility, 4th edn, Oxford: Oxford University Press.

Broadbridge, A.M. and Fielden, S.L. (2018), Research Handbook of Diversity and Careers, Cheltenham, UK and Northampton, MA, USA: Edward Elgar Publishing.

Burton, J. and World Health Organization (WHO) (2010), WHO Healthy Workplace Framework and Model: Background and Supporting Literature and Practices, Geneva: World Health Organization.

Cortina, L.M. (2008), 'Unseen injustice: Incivility and discrimination in organizations', Academy of Management Review, 33(1), 55-75.

European Parliament and of the Council of 4 (2003), 'Directive 2003/88/ concerning certain aspects of the organisation of working time', Official Journal L 299, 0009-0019.

Flin, R. (2007), 'Measuring safety culture in healthcare: A case for accurate diagnosis', Safety Science, 45(6), 653-67.

Fukuyama, F. (2004), State Building: Governance and World Order in the Twenty First Century, Ithaca, NY: Cornell University Press.

Girak, B. (2016), 'An exploratory investigation into the impact of downsizing on occupational stress and organisational commitment', Thesis, Edith Cowan University, accessed at https://ro.ecu.edu.au/theses_hons/1471.

Guediri, S. and Griffin, M. (2015), 'Organizational safety climate', in S. Clarke, T.M. Probst, F. Guldenmund and J. Passmore (eds), The Wiley-Blackwell Handbook of the Psychology of Occupational Safety and Workplace Health, London: Blackwell-Wiley.

Haas, P.M. (2004), 'Addressing the global governance deficit', Global Environmental Politics, 4, 1-15.

Health and Safety Executive (2013), Leading Health and Safety at Work: Actions for Directors, Board Members, Business Owners and Organisations of All Sizes, accessed October 2019 at: https://www.hse.gov.uk/pubns/indg417.pdf.

Health and Safety Executive (2014), Stress Related and Psychological Disorders in Great Britain 2014, accessed October 2017 at: http://www.hse.gov.uk/statistics/ causdis/stress/stress.pdf.

Health and Safety Executive (2018), Case Studies: Successful Leadership, accessed October 2019 at: https://www.hse.gov.uk/leadership/casestudies-success.htm.

Health and Safety Executive (2019), Corporate Manslaughter and Corporate Homicide Act 2007, accessed April 2020 at: https://www.hse.gov.uk/corpmanslaughter/about .htm.

Health Education England (2016), 'The talent for care: A national strategic framework to develop the healthcare support workforce', accessed October 2017 at http:// www.hee.nhs.uk/sites/default/files/documents/TfC\%20National\%20Strategic\% 20Framework_0.pdf.

Henehan, K. and Rose, H. (2018), Opportunities Knocked? Exploring Pay Penalties among the UK's Ethnic Minorities, London: The Resolution Foundation.

Hunt, C.M. and Fielden, S.L. (2016), Coaching for Women Entrepreneurs, Cheltenham, UK and Northampton, MA, USA: Edward Elgar Publishing. 
Institute of Directors (2017), The 2017 Good Governance Report, accessed May 2019 at: https://www.iod.com/news/news/articles/The-2017-Good-Governance-Report.

Kobrin, S.J. (2009), 'Private political authority and public responsibility: Transnational politics, transnational firms, and human rights', Business Ethics Quarterly, 19, 349-74.

Organisation for Economic Co-operation and Development (2015), G20/OECD Principles of Corporate Governance, available at: https://www.oecd-ilibrary.org/ governance/g20-oecd-principles-of-corporate-governance-2015_9789264236882-en.

Scherer, A.G., Baumann-Pauly, D. and Schneider, A. (2013), 'Democratizing corporate governance: Compensating for the democratic deficit of corporate political activity and corporate citizenship', Business \& Society, 52, 473-514.

Scholtz, F. (2020), 'Taken for granted: Ableist norms embedded in the design of online recruitment practices', in S.L. Fielden, M. Moore and G.L. Bend (eds), The Palgrave Handbook of Disability at Work, London: Palgrave Macmillan.

Strazdins, L., Welsh, J., Korda, R., Broom, D. and Paolucci, F. (2016), 'Not all hours are equal: Could time be a social determinant of health?', Sociology of Health \& Illness, 38(1), 21-42.

The Sunday Times Best Companies to Work For List (2019), accessed April 2019 at: https://www.b.co.uk/the-lists/.

Tatli, A. and Özbilgin, M.F. (2012), 'An emic approach to intersectional study of diversity at work: A Bourdieuan framing', International Journal of Management Reviews, 14(2), 180-200.

Taylor, M., Marsh, G., Nicol, D. and Broadbent, P. (2017), Good Work: The Taylor Review of Modern Working Practices, London: Great Britain, Department for Business, Energy \& Industrial Strategy.

van Tulder, R. (2010), 'Toward a renewed stages theory for BRIC multinational enterprises? A home country bargaining approach', in K.P. Sauvant, G. McAllister and W.A. Maschek (eds), Foreign Direct Investments from Emerging Markets: The Challenges Ahead, New York: Palgrave, pp. 61-75.

Weinberg, A., Sutherland, V.J. and Cooper, C.L. (2010), Organizational Stress Management: A Strategic Approach, London: Palgrave Macmillan.

Woolnough, H.M. and Fielden, S.L. (2017), Mentoring in Nursing and Healthcare: Supporting Career and Personal Development, Chichester: Wiley-Blackwell.

Yule, S., Flin, R. and Murdy, A. (2007), 'The role of management and safety climate in preventing risk-taking at work', International Journal of Risk Assessment and Management, 7(2), 137-51.

Zohar, D. (2010), 'Thirty years of safety climate research: Reflections and future directions', Accident Analysis \& Prevention, 42, 1517-22. 